Ibn Al-Haitham Jour. for Pure \& Appl. Sci. 32 (2) 2019

Ibn Al Haitham Journal for Pure and Applied Science

Journal homepage: http://jih.uobaghdad.edu.iq/index.php/j/index

\title{
Histomorphometrical Study of Placental from Male and Female Neonates of Diabetic Women
}

Estabraq A. Mahmoud

Department of Biology,

College of Education for Pure

Sciences, Ibn Al-Haitham,

University of Baghdad,

Baghdad, Iraq

estabraq.a@ihcoedu.uobaghdad.edu.i

\author{
Nahla A. Al-Bakri \\ Department of Biology, \\ College of Education for Pure \\ Sciences, Ibn Al-Haitham, \\ University of Baghdad, \\ Baghdad, Iraq \\ Ban J. Qasim \\ Department of Pathology, \\ College of Medicine, Al- \\ Nahrain University, Baghdad, \\ Iraq \\ nahlaalbakri62@gmail.com
}

Article history: Received 20 January 2019, Accepted 8 April 2019, Publish May 2019

Doi: 10.30526/32.2.2125

\begin{abstract}
Abstarct
Objective: To investigate occur the histomatrical alternations in placental terminal villi and their vessels of Iraqi diabetes (gestational diabetes and overt diabetes) and normal pregnancies were born male and female neonates. Methods: The hitometrical study of male and female terminal villi of 68 placentae in maternal diabetes mellitus (34 gestational diabetes, 34 overt diabetes (17 DM type 1 and $17 \mathrm{DM}$ type 2) and 34 normal placentae. These placentae obtained from Department of Obstetrics and Gynaecology in three hospitals in Baghdad city. Results: The study showed that there is a statistically significant with higher diameter in central and peripheral sections of the terminal villi and their vessels in male neonate. Moreover, terminal villous diameter in central and peripheral sections of placentae in both male and female neonates appeared highly significant differences $(\mathrm{P} \leq 0.001)$ between $\mathrm{DM}$ type 1 and DM type 2, but fetal blood vessels in this terminal villous did not record any significant difference $(\mathrm{P}>0.05)$. Conclusions: The current results concluded that increasing in diameters terminal villous and their fetal blood vessels of central and peripheral sections of placentae recorded increasing diameters of GDM peripheral sections of placentae in male neonate in comparison to placental sections of other study groups.
\end{abstract}

Keywords: Placentae, Histometrical, Gestational diabetes, Overt diabetes

\section{Introduction}

Placenta is the most essential fetal organ due to it is in control for interchange of all nutrients, oxygen and fluid from mother to fetus and elimination of fetal waste products. The placenta offers important data on the timing and etiology of numerous adverse events, counting fetal distress, neurologic injury, growth restriction, infections, mortality and several other fetal conditions. It also reproduces the intrauterine environment, assistances in identification of unknown maternal conditions, such as during diabetes mellitus [1]. Diabetes 
mellitus is a chronic, permanent condition that effects on body's ability usages the energy originate in food. There are three main types of diabetes: type 1 diabetes (DM1), type 2 diabetes (DM2) and gestational diabetes (GDM). Diabetes in pregnancy is essential because of increasing degrees of the disease and its outcome on maternal, fetal and neonatal health, such as preeclampsia, macrosomia, primary caesarean delivery, birth injury and clinical neonatal hypoglycaemia [2]. The placenta of diabetic women suffers a variability of structural and functional changes when compared with placentas from non-diabetic women [3]. At the third trimester of gestation type 1 diabetes finding are related to increase each of vessel volume, surface area, total diffusive conductance, intervillous and trophoblast volume and greater degrees of vascular dysfunction, containing increased branching and non-branching angiogenesis, probably the result of increased leakiness of fetal placental vessels [4,5]. Terminal villous volume and vessel length is improved in type 2 diabetes and gestational diabetes placentae compared to nondiabetic controls [6]. Thus, the aim of the present study is to examine the incidence of histomatrical alternations in placental terminal villi and their vessels of Iraqi diabetes (gestational diabetes and overt diabetes) and normal pregnancies were born male and female neonates.

\section{Materials and Methods}

Fresh placentae were obtained from Department of Obstetrics and Gynaecology in three hospitals in Baghdad at the period between 1 December 2016 and 1 may 2017. Three studying groups were analyzed: First group, women with uncomplicated, healthy with singleton pregnancies, the group was considered as control group (cases $n=34$ ). Second group included women with pregnancies complicated by gestational diabetes mellitus (GDM) (cases n=34) at third trimester with singleton pregnancies. The third group women with pregnancies complicated by overt diabetic mellitus (DM) (cases $n=34,17$ placentas type $1 \mathrm{DM}$ and 17 type $2 \mathrm{DM}$ ) at third trimester with singleton pregnancies too. The mothers' informed consents were gained according to Local Research Ethics Committee approval in Iraqi Ministry of Health. Placentae were cut and sampled for histological examination. Two samples were taken from the selected lobule of placenta one from the central area and other from the peripheral area. Fresh placental tissue pieces were placed in a labelled clean plastic container containing 10\% NBF solution [7]. Tissue samples from placentae after delivery were prepared for histometrical study according to the methods of [8]. Each of tissue samples were usually cut into small parts before another fixation then put the pieces of tissue into embedding cassettes. The water was removed from the parts to be embedded by bathing them consecutively in a graded sequence of mixtures of ethanol and water (70\% to $100 \%$ ethanol). Ethanol was then substituted with xylene. The tissue was placed in melting paraffin in the oven. The metal embedding model with paraffin were cooling. The hard blocks encompassing the tissues was then taken to a microtome and was sectioned to a thickness of $(5 \mu \mathrm{m})$. The sections was transferred to glass slides to be stained. Haematoxylin and Eosin staining was accomplished according to [9]. Sections were examined by compound light microscope (Meijitechno, Japan) with digital camera (Canon, Japan, 18 megapixels). The images were captured with a Live View Pro digital camera directly into the computer in advanced embryology laboratory, Department of Biology, College of Education for Pure Science (Ibn Al-Haitham), University of Baghdad then adding scale bars to all images by using ImageJ software. The data analysis was done using SPSS program version 15 and 18 (SPSS Inc., 


\section{Chicago, IL, USA).}

Diameter of terminal villi and blood vessels were measured in central and peripheral sections of studied groups that stained with $(\mathrm{H} \& \mathrm{E})$ by using stage, ocular, and reticle (eyepiece) micrometer at power 40x. To accurately calibrate the reticle with a stage ocular micrometer, bring into line the zero of the stage micrometers with the zero of the reticles. Then, prudently scan over until get the lines line over. After that, use a simple proportion to regulate the value that each line denotes in used reticle Figure 1. [10]. The diameters of terminal villi and their blood vessels were counted for five fields per slide, which were selected randomly for each section and mean of these diameters were calculated [11]. The preliminary processing of the data from the database was performed using the Microsoft Excel of the Microsoft Office 2013 software package.

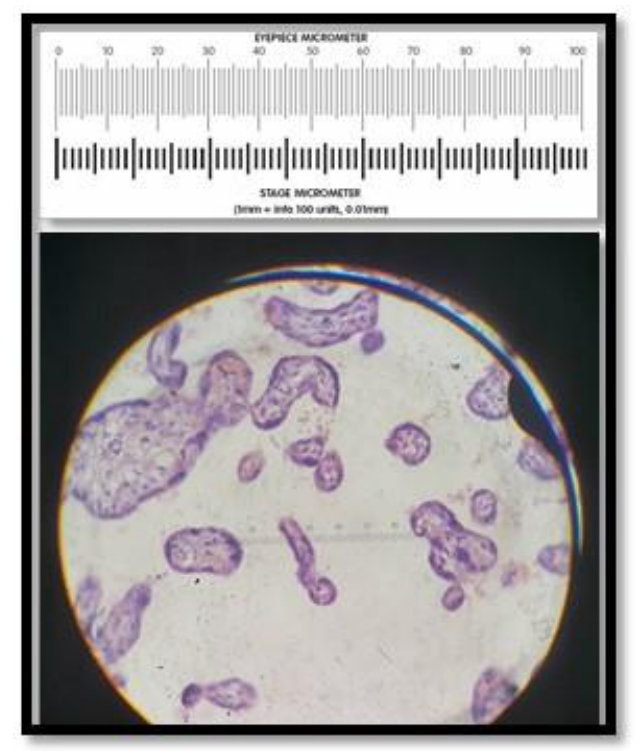

Figure 1. Reticle (eyepiece) micrometers with a stage ocular micrometer to calculate diameter of terminal villi.

Analysis of variance using one-way ANOVA and independent t-test were used as appropriate test for histometrical parametric data. All the data were obtainable in this study as mean \pm standard error of the mean (mean \pm SEM). The level of significance was at the limits of agreement (95\% confidence interval of the difference between the three groups, and values of $\mathrm{P} \leq 0.05$ and $\mathrm{P} \leq 0.001$ were reflected statistically significant and highly significant, individually between the studied groups.

\section{Results}

In comparison with terminal villi diameters of female and male neonatal illustrated in Figure 2, 3, terminal villi in male neonatal had larger diameter in all study groups and sections (central and peripheral). These increases showed highly significant differences $(\mathrm{P} \leq 0.001)$ in all study groups and sections except the central section of GDM group which showed no a significant difference $(\mathrm{P}>0.05)$ between males and females neonatal. Vessels diameter of terminal villi in male neonatal were dilated in all groups and sections compared with those of female neonatal and showed significantly higher difference $(\mathrm{P} \leq 0.001$ or $\mathrm{P} \leq 0.05)$ between three groups and sections, only peripheral section of control group presented no significant difference $(\mathrm{P}>0.05)$ as shown in Figures 2,4. In placentas of DM type 1 and type 2 sub-groups, diameters of terminal villi in males' neonates were found be more significant 
$(\mathrm{P} \leq 0.001$ or $\mathrm{P} \leq 0.05)$ when compared to diameters of terminal villi in females neonatal (central and peripheral sections). Peripheral section of male in DM type $2(73.50 \pm 3.03 \mu \mathrm{m})$ showed higher value compared with central section of same sub-group $(62.75 \pm 1.37 \mu \mathrm{m})$ and sections of DM type 1 sub-groups (central and peripheral) $(53.86 \pm 0.62$ and $63.41 \pm 1.03 \mu \mathrm{m})$ as shown in Figure 5. As well as, terminal villi blood vessels diameters in Figure 6. demonstrated significant differences $(\mathrm{P} \leq 0.001$ or $\mathrm{P} \leq 0.05)$ between male and female in placental sections of DM type 1 and type 2 sub-groups. Peripheral section of male in type 2 sub-group showed higher values $(12.50 \pm 0.37 \mu \mathrm{m})$ followed by peripheral section of male in type 1 sub-group $(12.27 \pm 0.53 \mu \mathrm{m})$.
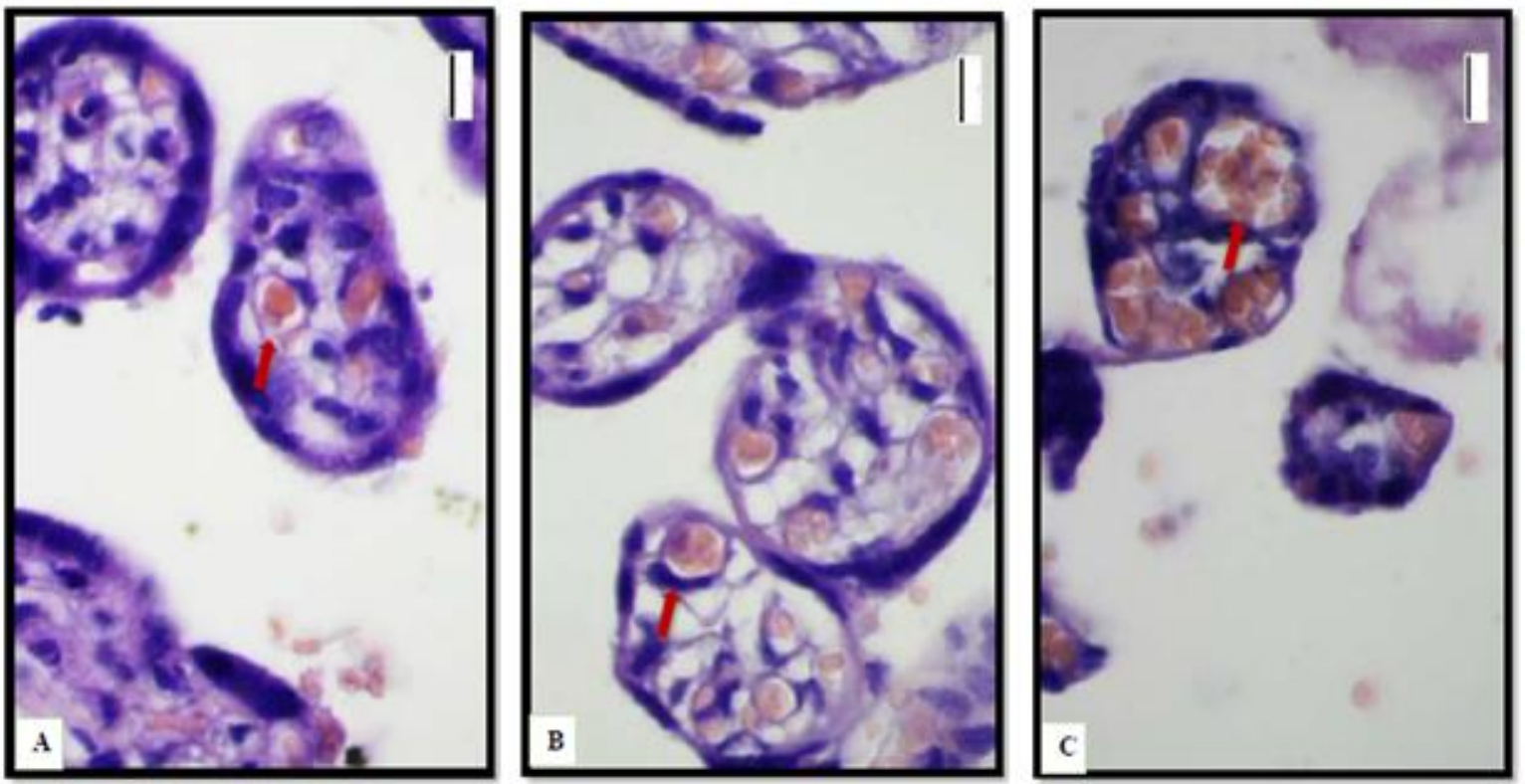

Figure 2. Section of placenta showing: A- Control group, normal terminal villi and their fetal blood vessel (red arrow). B and C- GDM and DM groups, alternation surface area of terminal villi and their fetal blood vessel in comparison with control group (arrow) (H \& E, 100X); Scale bar $20 \mu \mathrm{m}$.

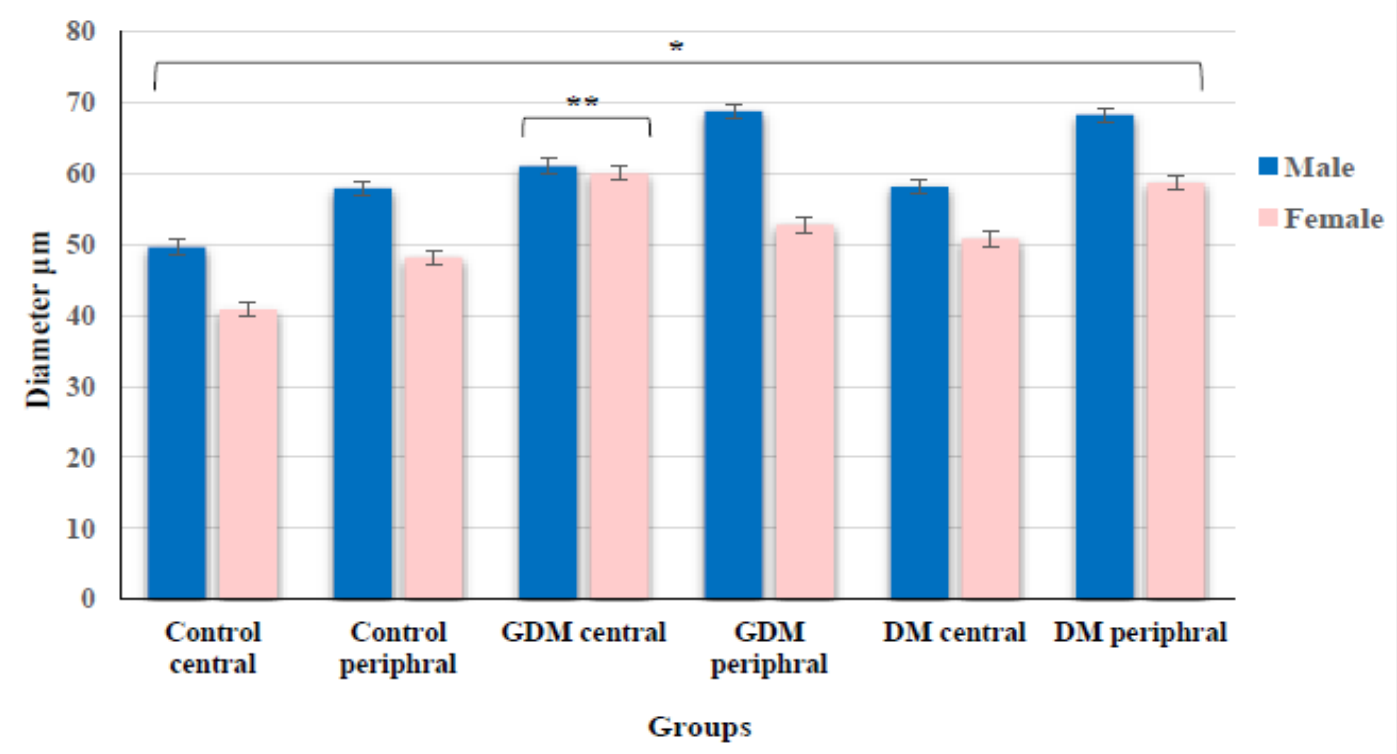

Figure 3. Comparison of terminal villi diameter between male and female neonatal placentas (central and peripheral sections) in three study groups. Data represents means \pm S.E.M. Statistical differences represented by *highly significant at $\mathrm{P} \leq 0.001$; **non significant at $\mathrm{P}>0.05$ (One-way ANOVA test). 
Ibn Al-Haitham Jour. for Pure \& Appl. Sci. 32 (2) 2019

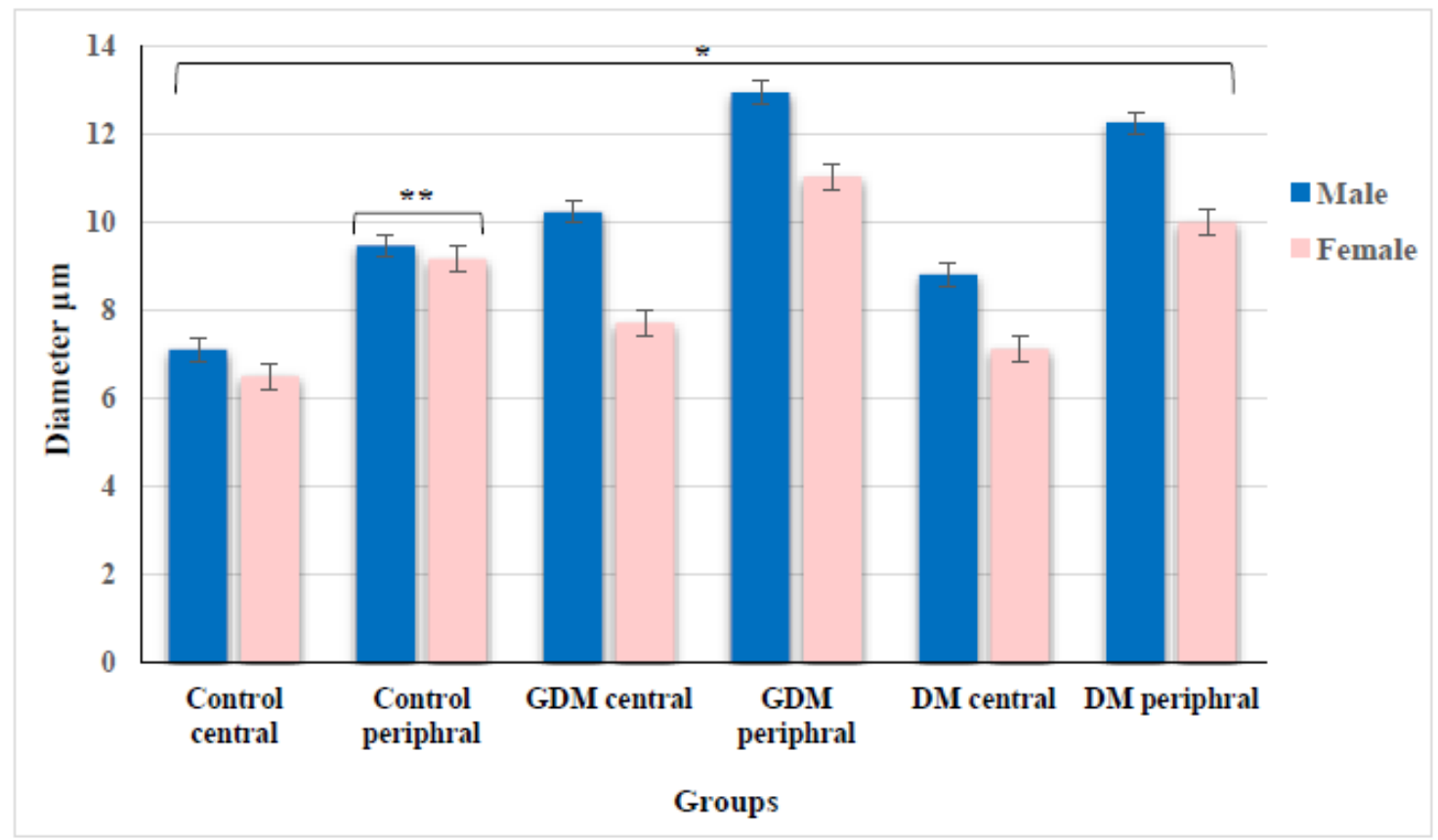

Figure 4. Comparison of fetal blood vessels in terminal villi between male and female neonatal placentas (central and peripheral sections) in three study groups. Data represents means \pm S.E.M. Statistical differences represented by *highly significant at $\mathrm{P} \leq 0.001$ or significant at $\mathrm{P} \leq 0.05$; **non significant at $\mathrm{P}>0.05$ (One-way ANOVA test).

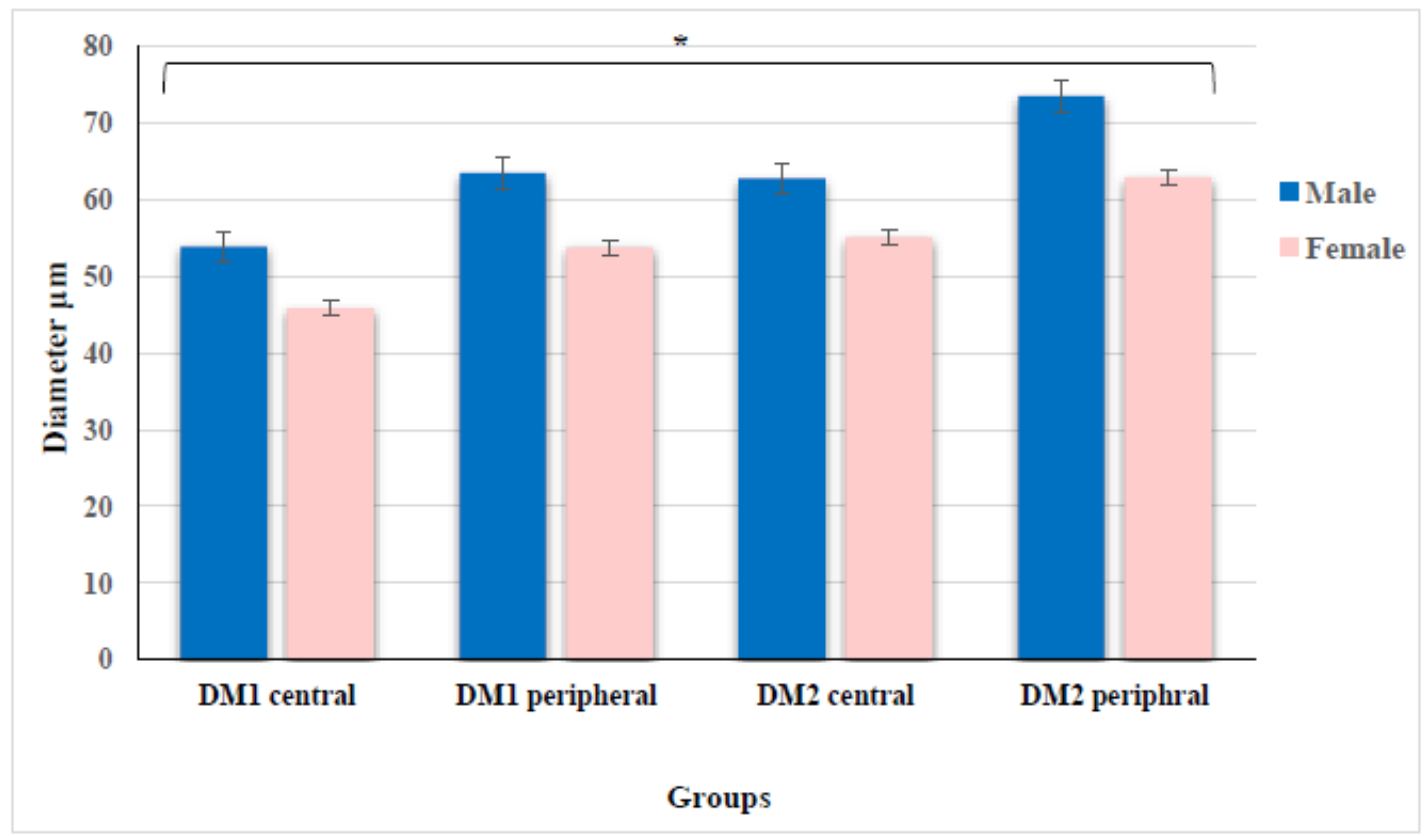

Figure 5. Comparison of terminal villi diameter between male and female neonatal placentas (central and peripheral sections) in DM type 1 and type 2 sub-groups. Data represents means \pm S.E.M. Statistical differences represented by *highly significant at $\mathrm{P} \leq 0.001$ or significant at $\mathrm{P} \leq 0.05$; ((2-tailed) independent). 


\section{Ibn Al-Haitham Jour. for Pure \& Appl. Sci. 32 (2) 2019}

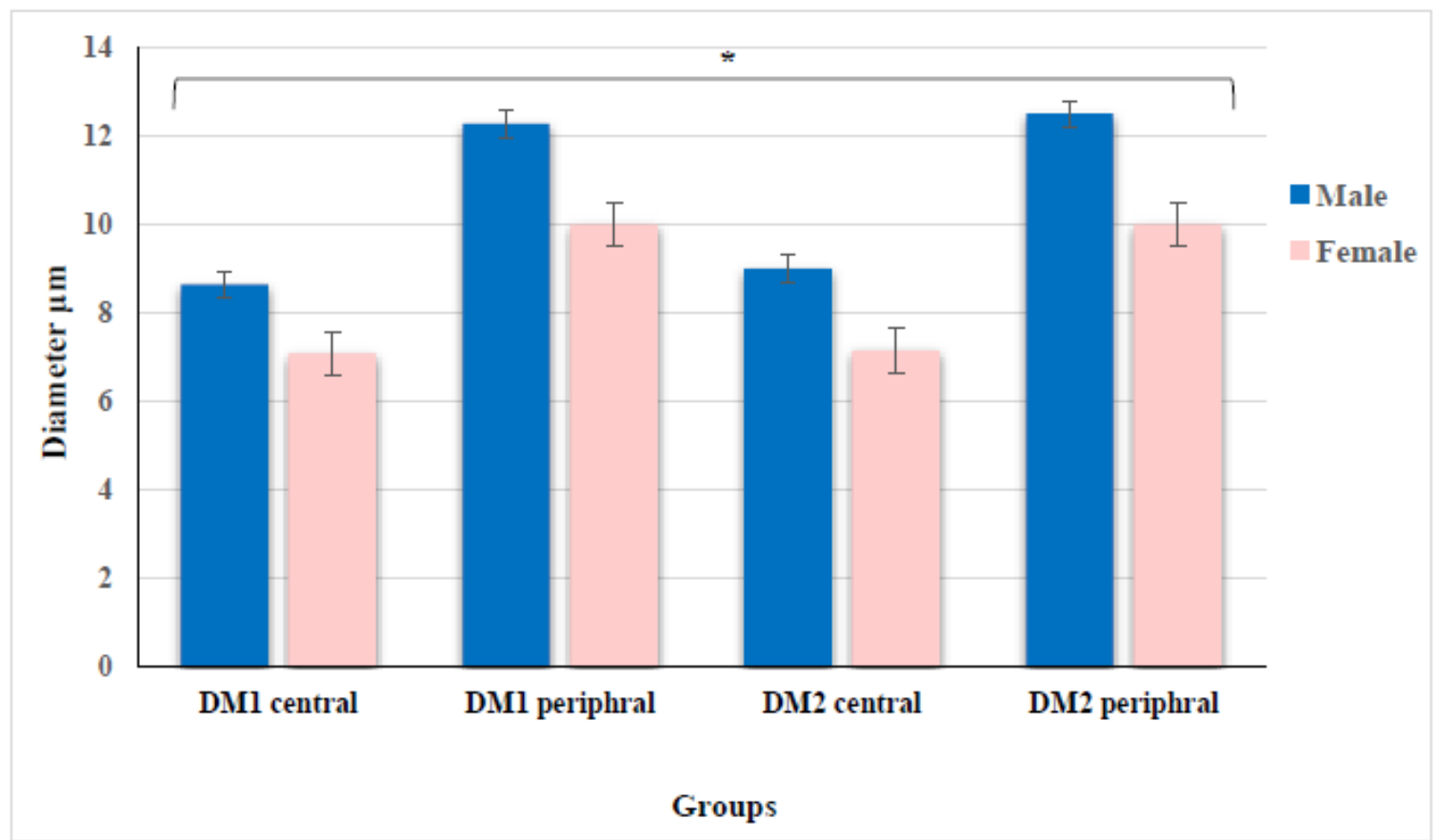

Figure 6. Comparison of fetal blood vessels in terminal villi according to gender of neonatal (central and peripheral sections) in DM type 1 and type 2 sub-groups. Data represents means \pm S.E.M. Statistical differences represented by *highly significant at $\mathrm{P} \leq 0.001$ or significant at $\mathrm{P} \leq 0.05$; ((2-tailed) independent).

\section{Discussion}

Histometrical study had confirmed that the combined diameter of terminal villous and their vessels are significantly greater in diabetic placentas, either GDM or DM groups. We found that those parameters also dependent on the gender of neonate. Thus, diameter of terminal villi and blood vessels in placentas of male foetuses was greater significantly than placentas of female foetuses. Those findings were corroborated in [12-14]. This parameter proposes the male placenta develops faster earlier in pregnancy and may be connected to the mechanism by which male foetuses were heavier at delivery [15]. Therefore, macrosomia related with maternal glucose intolerance was larger in male foetuses than female foetuses [16]. As well as some studies established that carrying male foetus increased the risk of maternal gestational diabetes in another gestation because of the association among a male gender foetus and maternal insulin resistance [17-19]. An amount of placentally consequent hormones may affect maternal insulin resistance, particularly, placental oestriol and lactogen, that may possibly increase with a bigger placental size [20, 21]. Although there were numerous similar placental features in type 1 and type $2 \mathrm{DM}$, but due to differ pathogenetic mechanisms of DM type 1 and DM type 2 sub-groups that effects on the placenta, the histometry of placentas of women with each type of DM are altered [22]. Regarding relation of gender with diameter of terminal villous and their vessels, this study recorded increasing diameters of terminal villi of both central and peripheral sections in males' neonates compared to diameters of terminal villi in female neonatal. As well as, terminal villi blood vessels diameters demonstrated significant differences between male and female in two placental sections (central and peripheral sections) of DM type 1 and DM type 2 sub-groups. Male and female placentas have different approaches to optimize condition. The male approach for responding to an adversarial maternal milieu is a simple approach few genes, proteins or functional alterations are complicated in the placenta, which eventually confirms 
continued development in a fewer than optimum maternal environment. This particular male reaction is related with a larger risk of preterm delivery, intrauterine growth restriction or death in utero if another confrontational event happens during the gestation. The female placenta reacts to an adversarial maternal environment with numerous placental gene and protein alterations that result in a decline in development without growth restriction. Thus, female changes in placental function and growth confirm survival in the occurrence of another confrontational event which may more cooperation oxygen supply or nutrient [23]. The finding in current study was in line with [24]. who suggest that severe placental alternation is more common in pregnancies with a male than with a female fetus.

\section{Conclusion}

Histomorphometrical study of terminal villous and their fetal blood vessels of central and peripheral sections of placentas recorded increasing diameters of GDM peripheral sections of placentas in male neonate in comparison to placental sections of other study groups that may be a result of chronic hypoxic alterations.

\section{References}

1. Kos, M. Placenta - a silent witness: clinical and forensic importance of placental examination. Materia Medica. 2012, 28, 2, 533-539, doi:10.5937/matmed1202533K.

2. Lowe, L.P.; Metzger, B.E.; Dyer, A.R.; Lowe, J.; McCance, D.R.; Lappin, T.R.; Trimble, E.R.; Coustan, D.R.; Hadden, D.R.; Hod, M.; Oats, J.J.; Persson, B. HAPO Study Cooperative Research Group. Hyperglycemia and adverse pregnancy outcome (HAPO) study: associations of maternal A1C and glucose with pregnancy outcomes. Diab. Care. 2012, 35, 574-580, doi: 10.2337/dc11-1687.

3. Baergen, R.N. Manual of Pathology of the Human Placenta; $2^{\text {nd }}$ ed; Springer Science+Business Media, LLC, New York, USA. 2011, doi:10.1007/978-1-4419-7494-5.

4. Cvitic, S.; Desoye, G.; Hiden, U. Glucose, insulin, and oxygen interplay in placental hypervascularisation in diabetes mellitus. Biomed. Res. Int. 2014, 2014, 12, 1-12, doi: 10.1155/2014/145846.

5. Bentley-Lewis, R.; Raspollini, M.R.; Roberts, D. Pathologic abnormalities of placental structure and function in diabetes. In: Textbook of Diabetes and Pregnancy, $3^{\text {rd }}$ ed. Taylor and Francis Group, LLC, Florida, USA, 2016, 91-96.

6. Khong, T.Y. The Placenta and Umbilical Cord. In: Keeling's Fetal and Neonatal Pathology, $5^{\text {th }}$ ed. Springer International Publishing, Cham, Switzerland, 2015, doi:10.1007/978-3-319-19207-9_2.

7. Yung, H.W.; Colleoni, F.; Atkinson, D.; Cook, E.; Murray, A.J.; Burton, G.J.; CharnockJones, D.S. Influence of speed of sample processing on placental energetics and signalling pathways: Implications for tissue collection. Placenta. 2014, 35, 2014, 103-108, doi:org/10.1016/j.placenta.2013.11.016.

8. Anderson, G.; Bancroft, J. Tissue processing and microtomy. In: Theory and Practice of Histological Techniques; $5^{\text {th }}$ ed, Churchill Livingstone Elsevier Ltd., Shanghai, China, 2002

9. Bancroft, J.D.; Layton, C. The hematoxylins and eosin. In: Bancroft's Theory and Practice of Histological Techniques, $7^{\text {th }}$ ed, Churchill Livingstone Elsevier Ltd., Shanghai, China. 2013 


\section{Ibn Al-Haitham Jour. for Pure \& Appl. Sci. 32 (2) 2019}

10. Sankar, K.D.; Bhanu, P.S.; Ramalingam, K.; Kiran, S.; Ramakrishna, B.A. Histomorphological and morphometrical changes of placental terminal villi of normotensive and preeclamptic mothers. Anat. Cell Biol. 2013, 46, 4, 285-290, doi: 10.5115/acb.2013.46.4.285.

11. Calderon, I.M.P.; Damasceno, D.C.; Amorin, R.L.; Costa, R.A.A.; Brasil, M.A.M.; Rudge, M.V.C. Morphometric study of placental villi and vessels in women with mild hyperglycemia or gestational or overt diabetes. Diab. Res. Clin. Pract. 2007, 78, 2007, 6571, doi:10.1016/j.diabres.2007.01.023.

12. Mayhew, T.M.; Sørensen, F.B.; Klebe, J.G.; Jackson, M.R. The effects of mode of delivery and sex of newborn on placental morphology in control and diabetic pregnancies. J. Anat. 1993, 183, 3, 545-552.

13. Mayhew, T.M.; Sørensen, F.B.; Klebe, J.G.; Jackson, M.R. Growth and maturation of villi in placentae from well-controlled diabetic women. Placenta. 1994, 15, 1, 57-65, doi: 10.1016/0020-7292(94)90372-7.

14. Mayhew, T.M. Enhanced fetoplacental angiogenesis in pre-gestational diabetes mellitus: The extra growth is exclusively longitudinal and not accompanied by microvascular remodelling. Diabetologia. 2002, 45, 1434-1439, doi 10.1007/s00125-002-0927-1.

15. Coall, D.A.; Charles, A.K.; Salafia, C.M. Gross placental structure in a low-risk population of singleton, term, first-born infants. Pediatr. Dev. Pathol. 2009, 12, 3, 200210, doi:10.2350/08-02-0413.1.

16. Clifton, V.L. Sex and the Human Placenta: Mediating Differential Strategies of Fetal Growth and Survival. Placenta. 2010, 24, 31, S33-S39, doi:10.1016/j.placenta.2009.11.010.

17. Sheiner, E.; Levy, A.; Katz, M.; Hershkovitz, R.; Leron, E.; Mazor, M. Gender does matter in perinatal medicine. Fetal Diagn. Ther. 2004, 19, 4, 366-369, doi:10.1159/0000 77967.

18. Retnakaran, R.; Shah, B.R. Fetal Sex and the Natural History of Maternal Risk of Diabetes during and After Pregnancy. J. Clin. Endocrinol. Metab. 2015, 100, 7, 25742580, doi:10.1210/jc.2015-1763.

19. Retnakaran, R.; Kramer, C.K.; Ye, C.; Kew, S.; Hanley, A.J.; Connelly, P.W.; Sermer, M.; Zinman, B. Fetal sex and maternal risk of gestational diabetes mellitus: the impact of having a boy. Diab. Care. 2015, 38, 5, 844-85, doi:10.2337/dc14-2551.

20. Toriola, A.T.; Vääräsmäki, M.; Lehtinen, M.; Zeleniuch-Jacquotte, A.; Lundin, E.; Rodgers, K.G.; Lakso, H.A.; Chen, T.; Schock, H.; Hallmans, G.; Pukkala, E.; Toniolo, P.; Grankvist, K.; Surcel, H.M.; Lukanova, A. Determinants of maternal sex steroids during the first half of pregnancy. Obstet. Gynecol. 2011, 118, 5, 1029-1036, doi:10.1097/AOG.0b013e3182342 b7f.

21. Walsh, J.M.; Segurado, R.; Mahony, R.M.; Foley, M.E.; McAuliffe, F.M. The Effects of Fetal Gender on Maternal and Fetal Insulin Resistance. PLoS ONE. 2015, 10, 9, 1-13, doi.org/10.1371/ journal.pone.0137215.

22. Starikov, R.; Inman, K.; Chen, K.; Lopes, V.; Coviello, E.; Pinar, H.; He, M. Comparison of placental findings in type 1 and type 2 diabetic pregnancies. Placenta. 2014, 35, 12, 1001-1006. doi: 10.1016/j.placenta.2014.10.008.

23. Renzo, G.C.; Picchiassi, E.; Coata, G.; Clerici, G.; Brillo, E. Is there a sex of the placenta. J. Pediatric Neonatal Individualized Med. 2015, 4, 2, 240-246.doi:10.7363/0 40246.

24. Edwards, A.; Megens, A.; Peek, M.; Wallace, E.M. Sexual origins of placental dysfunction. Lancet. 2000, 355, 203-204, doi.org/10.1016/S0140-6736(99)05061-8. 